\title{
Risk, Reward, and Scientific Ontology: Reply to Bryant, Psillos, and Slater
}

\author{
ANJAN CHAKRAVARTTY University of Miami
}

ABSTRACT: Scientific Ontology: Integrating Naturalized Metaphysics and Voluntarist Epistemology contends that ontological commitments associated with scientific inquiry are infused with philosophical commitments. Interpretations of scientific ontology involve (what I call) metaphysical inferences, and furthermore, there are different ways of making these inferences, on the basis of different but nonetheless rational epistemic stances. If correct, this problematizes any neat distinction between naturalized and other metaphysics, and dissolves any presumption of there being a uniquely correct answer to ontological questions connected to the sciences. In this paper, I consider some weighty challenges to these contentions by Amanda Bryant, Stathis Psillos, and Matthew Slater.

RÉSUMÉ : Dans Scientific Ontology: Integrating Naturalized Metaphysics and Voluntarist Epistemology, je soutiens que les convictions ontologiques associées à la recherche scientifique sont imprégnées de convictions philosophiques. Les interprétations de l'ontologie scientifique impliquent ce que j'appelle des inférences métaphysiques et, qui plus est, il existe différentes façons de faire ces inférences sur la base de positions épistémiques différentes, mais néanmoins rationnelles. Si cette analyse est juste, elle problématise toute distinction nette entre la métaphysique naturalisée et les autres types de métaphysique, et dissout toute présomption qu'il existe une seule bonne réponse aux questions ontologiques liées aux sciences. Dans cet article, je considère quelques-uns des importants défis qu'Amanda Bryant, Stathis Psillos et Matthew Slater posent à l'endroit de ces affirmations.

Dialogue 60 (2021), 43-63

(C) The Author(s), 2021. Published by Cambridge University Press on behalf of the Canadian Philosophical Association/l'Association canadienne de philosophie. This is an Open Access article, distributed under the terms of the Creative Commons Attribution licence (http://creativecommons.org/licenses/by/4.0/), which permits unrestricted re-use, distribution, and reproduction in any medium, provided the original work is properly cited.

doi:10.1017/S0012217320000311 
Keywords: scientific ontology, naturalized metaphysics, metaphysical inference, epistemic risk, epistemic stances, stance voluntarism, permissive rationality

\section{Introduction}

My commentators in this symposium - Amanda Bryant, Stathis Psillos, and Matthew Slater - have trained a great deal of incisive attention on my book, Scientific Ontology. I know this because they have been all too successful in pushing and pulling me in many challenging directions. Perhaps by way of compensation, they have also done an excellent job of outlining the principal ideas (my thanks here to Bryant for starting her piece with a very helpful summary ${ }^{1}$ ), and have thus saved me from doing much of this myself. Consequently, let me begin by simply recapping the basic motivation. The central idea of the book is, hopefully, to propose a clear picture of what naturalized or scientific metaphysics $i s$, and along the way, to argue that, as it happens, there are different and indefeasible ways of conceiving of where the boundary lines are between genuinely scientific ontology, and what might then count as a more rarefied activity practised by metaphysicians who are not themselves engaged with the sciences, or at least, not in any substantive way. In this paper, I will address several core issues at the intersections of my critics' concerns and, thereby, in varying levels of detail, touch on most of the rest of their concerns as well. To these ends, let me start with the key, putative distinction between naturalized and nonnaturalized metaphysics.

\section{Terms of Art: Metaphysical Inference and the $\boldsymbol{A}$ Priori}

What is the foremost difference between those who are especially sympathetic to naturalistic inquiry and those who are indifferent or attracted, to some greater degree, to other forms of inquiry into the nature of the world? Fundamentally, I believe, the difference has to do with different assessments of the extent to which our forms of inquiry are connected, and how well, to specifically empirical investigation. This is an old idea. It was, for example, at the heart of early modern debates between the empiricists and the rationalists. From the perspective of the present it is clear, I submit, that there is a pivotal sense in which, over the course of the last century, and certainly among the naturalistically inclined, empiricists ultimately won that debate. Of course, this victory must be understood properly and not overstated. They won, not in the sense of convincing everyone that knowledge of the world is limited to what we can experience, but in the sense of convincing us that the gold standard for inquiry - inquiry that is our best bet for producing knowledge of the world - is empirical investigation. In other words: observation; intervention; manipulation; experimentation; making predictions of significant precision on the basis of our theories and models and then seeing whether they are, in fact, borne out.

1 Bryant, Section 1. For yet more fine help, see Psillos, Section 1, and Slater, Section 2. 
When those who are naturalistically inclined criticize others for not appreciating this, there is a clear target in view: non-empirical, or a priori theorizing. Bryant asks why I do not simply ground scientific ontology in science simpliciter. $^{2}$ My answer is that this would be to overlook the sense in which empiricists won their debate. Some aspects of the modern sciences are thoroughly empirical, and others much less so. By the standards of naturalistically inclined philosophers themselves, this should already suggest an ordering of degrees of belief with respect to different aspects of the sciences. Across their breadth, the sciences incorporate very different methods of investigation, and across their history, what counts as scientific has changed substantially, and there is nothing to preclude yet further change. Given the variability of forms of scientific inquiry, past, present, and (likely) future, it would be strangely undiscriminating simply to index one's beliefs regarding ontology to such an amazing variety and potentially changeable grab bag of investigative methods. As a matter of historical and institutional contingency, our sciences $d o$ incorporate impressive techniques of empirical investigation, but there are degrees. Thus, what is crucial here in reflecting on ontology is not the institution of science nor science simpliciter — these are not sufficiently discerning categories — but the degree to which any particular investigation, including any given scientific investigation, is empirical.

In the book, I argue that even the most empirically well-supported inferences in the sciences involve at least some a priori manoeuvring, and that even the most abstruse analytic metaphysics is weakly a posteriori in that it is generally intended, by design and in order to be minimally viable, to feature a weak sort of empirical adequacy in being compatible with the relevant empirical data, whatever they may be. Given these twin assertions, is there no distinction to be made between naturalized and non-naturalized metaphysics after all? Certainly, there is; what this distinction turns on is the degree of metaphysical or a priori manoeuvring involved. I will return to this idea of degrees or 'magnitudes' of metaphysical inference momentarily, but before it can get off the ground, the more basic notion of a metaphysical inference must be found compelling, and some of my interlocutors are not yet convinced. Hence, before confronting possible worries about what it might mean for an inquiry into putative aspects of the world to incorporate metaphysical inferences that are more or less empirical, or more or less a priori, let me first attempt to rescue the underlying notion of metaphysical inference from their concerns.

Some may be uneasy about assigning metaphysical inference the rather broad remit suggested above, while simultaneously describing it in terms of a priori thinking. ${ }^{3}$ Is there really anything significantly a priori about inferring the

2 Bryant, Section 2.

3 To set one possible concern aside: it does not entail the idealism that one might read into Psillos' remarks in passing (though I doubt he intends this reading himself), in 
existence of electrons on the basis of the explanatory power their existence would afford the results of empirical investigations? Let us untangle two threads, here. First, the question of whether the inference is significantly a priori raises the issue of degrees, viz., degrees of a prioricity that are significant or not, as the case may be. Second, leaving this first question aside for the moment, there is the prior question of whether there is anything a priori here at all. My affirmative answer stems from the fact that as soon as one appeals to the explanatory power of the existence of something to give an account of the empirical data, one goes beyond those data. This is all I mean when I say that the inference has an a priori dimension. Ampliative inferences require that we go beyond what is entailed by the empirical evidence. When challenged to defend these inferences, we have no option but to explain and defend our inductive practices: our inferences to the best explanation, or whatever else one thinks is happening in ampliative reasoning. However one precisifies this, the inductive leap is from the data; it is not itself given in the data. And yet, explanatory considerations are often given evidential weight. It is in this sense that these inferences have an $a$ priori dimension.

I admit, then, to being puzzled by Psillos' concern that there is something "very odd" about the claim that relying on explanatory considerations in this context has an a priori dimension. ${ }^{4}$ His counterclaim is that, while this may be so, these considerations may be justified nonetheless in an a posteriori way - for example, by noting how taking them seriously has "contributed to the acceptance of well-founded theories." Let me speculate that by "wellfounded" Psillos intends something like: developed and established on the basis of ample empirical evidence. It is unclear to me why this sort of a posteriori justification of the use of explanatory considerations should undermine my own claim about how these considerations function in a priori ways in inferences to ontological conclusions. Imagine two, seventeenth-century natural philosophers debating how best to interpret Newton's account of gravitation. Both hold that the account is well founded, but one thinks that its impressive empirical success is best explained in terms of the existence of gravitational forces, while the other is not committed to the existence of forces as such. The point here is simply that the significant a posteriori evidence they share regarding the success of the account is compatible with different ontological interpretations, resting on different assessments of how far the relevant explanatory considerations can take us.

\section{(continued)}

his Section 1 (emphasis mine): "If what we say there is (and, ultimately, what there is) depends on (the adoption of) an epistemic stance ..."; "Given that what there is depends on what epistemic policy is adopted ..."

4 Psillos, Section 2.

Ibid. 
Interestingly, the idea that there is something not-strictly-empirical involved in ampliative inference - in extending beyond the content of the premises, even when they are themselves empirical - seems less controversial in discussions of induction in the abstract, and more controversial when agents are challenged to defend particular inductive inferences. I suspect that controversy arises here in part by conflating the two threads mentioned above: the idea that there is an $a$ priori dimension to ontological inferences, even in the sciences, and the judgement that, in some cases, this dimension is properly viewed as being (in)significant. My use of the term 'metaphysical inference' is intended to do justice to the former idea; it is neutral regarding the latter. Another worry here may stem from identifying my appeal to explanation in this context with a very specific theory of inference, namely, inference to the best explanation (IBE), which some dislike for independent reasons. However, while speaking (as I do) of commonly cited, good-making features of explanation is compatible with IBE - as in Peter Lipton's discussion of features constituting explanatory "loveliness," and whether "loveliness" is indicative of "likeliness" ment. What is crucial to the notion of metaphysical inference is simply that there is an a priori dimension to giving explanatory considerations evidential weight. IBE is but one view of how this is done.

As Psillos notes, this conception of metaphysical inference has the consequence that even inferences to the existence of observable objects may count as metaphysical, since (as one might argue) their existence may offer "the best explanation of the patterns in our sensory contents." "This, he contends, should lead us to doubt the usefulness of the idea altogether: if it is metaphysical inference "all the way up and all the way down," then "no useful category is captured by the expression "metaphysical inference'." 8 This strikes me as hasty. Does it follow, from the fact that all of the members of a class share a property, that attributing this property is unilluminating? If the members of the class of concrete objects all had mass, would we say that attributing mass is useless or uninformative? One important fact about mass is that it admits of degrees, which is relevant to an understanding of the differential natures and behaviours of members of the class. Armed with my conception of metaphysical inference, I believe we are well equipped to see how some empiricists and even some scientific realists, who are generically critical of metaphysics, are confused. What they are objecting to is not, on pain of undermining their own commitments, metaphysical inference simpliciter, but rather degrees of metaphysical inference that are, ex hypothesi, incapable of producing warranted belief. This brings me, finally, to the idea of magnitudes of metaphysical inference.

\footnotetext{
6 Lipton, 2004/1991, Chapters 4, 9.

7 Psillos, Section 2.

8 Ibid.
} 


\section{Magnitudes of Metaphysical Inference and Epistemic Risk}

One of the principal themes of the book is that our understanding of what we are doing and achieving when we engage in ontological theorizing is seriously incomplete unless we carefully consider the epistemology of this theorizing. Key to this, I believe, is the idea of epistemic risk, or as Slater puts it, "epistemic security." Epistemic risk concerns how confident we are in our ability to judge whether a proposition is true or false. If we judge the risk to be high, that means we lack this confidence. If the perceived risk is low, we are typically happy to say that the proposition is true or false. I give an account of how, in the context of scientific ontology, we assess degrees of epistemic risk. In broad terms, I take this assessment to ride on a consideration of two factors. The first is what I call 'empirical vulnerability,' which concerns how susceptible a proposition is to empirical testing. The second is explanatory power, which concerns how well an ontological posit satisfies criteria that are commonly associated with good explanations of empirical observations, such as coherence with background knowledge, unification of otherwise disparate-seeming phenomena, and so on. As a starting point for thinking about the epistemology of ontological theorizing, add to this the observation that when, in any given case, we fill in the details of this schematic picture, what we find is that different people end up assessing epistemic risk in rather different ways.

The import of empirical vulnerability is fairly uncontroversial - one might diagnose this as a reflection of the fact that, as mentioned earlier, nearly everyone is now an empiricist in this one, limited sense. The import of explanatory power, however, is deeply controversial. Given this, some in the audience ${ }^{10}$ wondered whether it would be better simply to assess epistemic risk solely on the basis of empirical vulnerability and dispense with explanatory power altogether. As I have suggested, though, reasoning ampliatively on the basis of our immediate experience (whether in science or otherwise), in order to draw ontological conclusions, inevitably brings us into the territory of giving explanations and assessing their strength. Thus, it seems that if we are to have any scientific ontology at all, some assessment of explanatory considerations is unavoidable. This is compatible, of course, with the fact that some metaphysical inferences involve a further leap from the data than others; this is where controversies over the import of explanatory power begin. Inferring that there are microscopic organisms on the basis of using a light microscope involves a much smaller leap than using the Large Hadron Collider at CERN to infer that there are Higgs bosons. And there are many, seemingly, prima facie rational people who believe in entities that are not even amenable to detection at all, certainly not in any direct way — say, neutrinos before 1956, or Higgs bosons

\footnotetext{
9 Slater, Section 2.

10 At our APA Symposium (see Acknowledgements).
} 
before 2012 - on the basis of explanatory considerations. (I will return to the subject of rationality later.)

It is possible, no doubt, to contest this entire way of proceeding. Is it not the job of the sciences to take all of this into account and do the work for us? A wellestablished theory in a well-established domain of science describes certain things, one might say; philosophers add nothing useful by ruminating on magnitudes of metaphysical inference that pertain to aspects of these theories. Indeed, one might question whether it is even possible to order aspects on a scale of epistemic risk. Psillos suggests that empirical testing is holistic, in which case all aspects of scientific theories are in principle empirically vulnerable. ${ }^{11}$ Now, confirmational holism is controversial, but even if one grants the basic idea, it does not entail that everything in a theory is confirmed by evidence to the same degree. The thought that some aspects of theories are confirmed to higher degrees than others is explicitly or implicitly defended, for instance, in all forms of selective scientific realism (various forms of entity realism, structural realism, etc.) - a banner under which I would include Psillos' own, famous prescription that what scientific realists should be realists about are those particular aspects of theories that are required — to which we must appeal — in order to generate their novel predictive success. ${ }^{12}$ I side with those who believe that differential degrees of support are discernible, a group whose ranks include scientists themselves.

Psillos also points out that there may be cases in which explanatory power trumps a lack of empirical vulnerability, ${ }^{13}$ and with this I agree completely: the neutrino and Higgs boson cases above (with timeframes prior to detection duly noted) are examples of explanatory trumping. From this, however, he derives the contention that there are no differences in epistemic risk corresponding to different magnitudes of metaphysical inference, undermining once again, it seems, the idea of differential degrees of support. Try as I might, I have trouble reconstructing the derivation. Granted, talk of degrees or magnitudes here is something of a figure of speech; I do not mean to suggest that we have anything resembling a quantitative scale of such an ordering. Nevertheless, there are orderings. In passing above, I maintained that the relevant magnitude in inferring the existence of microscopic organisms is much smaller than that involved in inferring the existence of Higgs bosons. Scientific realists are typically comfortable with larger magnitudes of metaphysical inference than some empiricists. And so on. Debates about whether or to what extent explanatory power is evidentially weighty are formulated in precisely these terms (if perhaps using different terminology), contesting whether certain inferences are sufficiently 'close' to the data or 'go too far.' Is this not an intuitive idea?

\footnotetext{
11 Psillos, Section 3.

12 Psillos, 1999, Chapters 5-6.

13 Psillos, Section 3.
} 
Intuitions aside, one might well hope for a more refined conception of how these assessments of greater and lesser magnitudes of metaphysical inference are made. In the book, I sketch the beginnings of a more detailed account in terms of several factors, including the confirmatory relevance of novel predictions that turn out to be correct versus the mere accommodation of data already known, the extent to which ontological posits are susceptible to serious underdetermination, and what I call 'experiential distance,' which concerns how directly or indirectly such posits are connected to empirical data - for example, in terms of the lengths, quality, and reliability of the causal chains involved in putative detection (where this is possible). While the exploration of this space of considerations that play a pivotal role in determining how magnitudes of metaphysical inference are assessed is still at an early stage, it seems undeniable that considerations like these are crucial in facilitating ontological commitments. At the same time, it is clear that different epistemic agents do not generally make these sorts of assessments in all the same ways, which produces the various interpretations of scientific theories and models with which we are now all too familiar. Let me turn to this idea next.

\section{The Nature and Role of Underlying Epistemic Stances}

The key concept to which I appeal in describing the intersection of epistemology and the relevance of degrees of metaphysical inference to ontological commitment is the notion of a stance. This rightly suggests an important progenitor in Bas van Fraassen's book, The Empirical Stance, though similarly formative thoughts have been in the air for some time, appearing in (among other places) work by Alison Wylie, Arthur Fine, and John Worrall. ${ }^{14}$ My own development of this concept focuses very specifically on the notion of an epistemic stance, which I characterize as a collection of attitudes, values, perspectives, and policies relevant to the assessment of evidence. While not themselves propositional — in the sense that they are not, strictly speaking, truth apt or truth evaluable - stances are nonetheless relevant to the production of putatively factual beliefs. Citing a non-exhaustive list of stances relevant to scientific ontology, I discuss what I call the 'deflationary stance,' the 'empiricist stance,' and the 'metaphysical stance.' The latter two are especially significant in thinking about how different agents draw lines between domains of ontological theorizing in which they have confidence that beliefs are warranted, and domains in which they do not.

As the rather general labels for the three epistemic stances just mentioned may well suggest, these are very broad categories. In actual epistemic practice, each of them is surely representative of a great many, finer-grained exemplifications. To give just one, perhaps obvious illustration of this, consider a phenomenon to which I have alluded several times already: those who adopt the metaphysical

14 See Wylie, 1986; Fine, 1996/1986; Worrall, 2000; van Fraassen, 2002. 
stance may nonetheless disagree with one another regarding just how expansive a positive attitude toward greater magnitudes of metaphysical inference is appropriate. It is possible to adopt a more or less cautious attitude toward epistemic risk even among those who share the metaphysical stance, broadly conceived. Whatever grain of analysis best suits the task at hand, the crucial idea here is that, as Slater notes, stances comprise different takes on how to make judgements about epistemic risk, and thus scientific ontology, that are "more or less austere, ... more or less risk-prone." "15 And the idea that a stance determines where one draws lines between domains of theorizing in which belief seems appropriate, and domains in which it seems better to remain agnostic, raises an important question about what a domain is, exactly.

It is natural to think of domains as being delineated by ontological questions or topics. While this is certainly what I have in mind, perhaps it is worth clarifying further how even (what may appear as) small alterations to questions often take us from one domain of topics into another. ${ }^{16}$ Giving answers to what may reasonably seem closely connected ontological questions sometimes requires engaging with topics that feature arguments involving significantly different degrees of metaphysical inference - generally, the greater the ontological resolution of the question, the greater the magnitudes of metaphysical inference involved in considering it. Is negative charge a state-independent property of electrons? This question specifies a topic at a level of generality that would appear to require no consideration of the precise ontology of properties. By way of contrast, one might ask: is negative charge a state-independent dispositional property of electrons? Here, part of what is at stake is whether charge is a disposition. This represents a change, in my terms, of domains of inquiry, since altering the previous question has introduced a new range of possible evidence and arguments for settling the question at issue. Domains are thus located along a spectrum of magnitudes of possible metaphysical inference, and stances are what determine which domains we take to be productive of warranted belief.

Having sketched an account of how stances underlie assessments of empirical vulnerability and explanatory power, and thus judgements of epistemic risk associated with ontological beliefs, let me now confront Psillos' charge that this has things back to front. ${ }^{17}$ It is not on the basis of stances that we form beliefs, he thinks, but rather, it is on the basis of our beliefs that we determine our stances. The stances we adopt are a function of the beliefs we form, not vice versa. For example, one may note that one believes in electrons, viruses, and tectonic plates, and that furthermore, lacking such knowledge would be epistemically impoverishing, and then on the basis of these beliefs adopt a stance that conforms to them: some version of the metaphysical stance. This points to

\footnotetext{
15 Slater, Section 2.

16 Questions regarding domains arose in our APA Symposium.

17 Psillos, Section 5.
} 
an important respect in which I suspect we are talking past one another. Clearly, one might note that in various evidential circumstances one forms beliefs that are typical of, say, scientific realists (who, across their breadth, adopt versions of the metaphysical stance), and then, upon reflection, identify oneself this way. But scientific realism is not a stance; it is a view, an account of scientific knowledge. It is standardly equated with a number of general and specific claims about the existence of scientific observables and unobservables - that is, with assertions of these propositions. Thus, granted, one might take one's assertion of scientific realism to follow from a consideration of the beliefs that one takes to be warranted in scientific contexts. But this is not an indictment of my account of stances.

On my view, the reason that scientific realists assert these propositions is that they adopt - are operating with — some version of the metaphysical stance, in accordance with which they judge that propositions regarding these subject matters are good bets for knowledge. Lacking a stance, they would have no inclinations at all regarding the formation of these beliefs, or for suspension of judgement where that seems more appropriate. This may make it sound as though one must first recognize one's stances in an explicit or conscious way, and then proceed to form beliefs, but this is rarely what happens in practice. Our stances are often unconscious and thus hidden. We regularly form beliefs without reflecting on our stances at all. The evidence simply strikes us as sufficiently compelling to assert or to deny a proposition, or it does not and we suspend judgement instead. This reveals one sense in which Psillos is surely correct that beliefs may come before stances (though not in the way he intends): a catalogue of one's beliefs may help, upon reflection, to illuminate one's stances — what sorts of demands for explanation one takes seriously, what sorts of risk tolerance one has in inferring the existence of entities, events, and processes, such that one ends up in certain doxastic states. But this is merely to say that reflection on our beliefs can help us to understand the stances with which we are operating. Without them, we would be paralyzed in the face of evidence.

Consequently, when Psillos contends that "we have not yet been told anything about how belief is justified,"18 I must protest. The entire account of how epistemic stances facilitate the formation of doxastic attitudes in evidential contexts, through assessments of epistemic risk, involving empirical vulnerability and explanatory power and different conceptions of how these parameters stack up - a book-length elaboration, I thought - is an exploration of how belief is justified and, more specifically, what this means in the context of naturalized or scientific ontology. Now, having thus protested, I appreciate that for all I have said here thus far, one might view all of the content to which I have just alluded as part of a merely descriptive story of how belief and agnosticism in the sphere of scientific ontology come to be. Justification is a normative notion.

18 Ibid. 
Even if stances are the lynchpin of a descriptive account of how people manifest doxastic attitudes, one might nonetheless argue that they are, at best, merely constitutive of how people feel or take themselves to be justified upon reflection, not constitutive of justification itself. This worry is no doubt amplified by my claim that stances are in some sense chosen. Let me turn to the latter issue next, before concluding with a discussion of what ultimately serves as the normative piece of this puzzle: a view of rationality that allows for the co-existence of different and conflicting stances.

\section{Stance Voluntarism, Doxastic Voluntarism, and 'Choice'}

First, then, let us consider the issue of choice, or voluntarism in epistemology. This is a topic of significant debate more generally and, therefore, an obvious lightning rod for concern. As it happens, though, the most natural, understandable concerns about voluntarism do not arise in my application of it here, to stances, and I suspect that the most pressing worries about stance voluntarism are based on misunderstandings of what it entails. Controversy surrounding voluntarism as it is most commonly discussed is not surprising - the notion that we are in a position to choose anything in relation to belief may appear whimsical initially. I can no sooner choose to believe that I am 6 foot 3 inches (160 $\mathrm{cm})$ tall, or that there are no such things as protons, than I can choose to believe that it is raining here outside my office window on yet another glorious morning in the Sunshine State. This is at least part of the incredulity I detect when Bryant objects that the notion of choosing epistemic stances is neither phenomenologically adequate, because we are typically unaware of any such choosing, nor plausible, since typically we do not choose the values associated with stances, "we just have them." "It is also present in Psillos' observation that "I do voluntarily believe that $p$; hence I know that $p$ " is a fallacy. And so is "I do voluntarily believe that $p$; hence $p . " 20$

Understandable reactions such as these generally turn on one (or both) of two assumptions, both of which I would deny. The first assumption is one that neither Bryant nor Psillos actually makes, though it is surely encouraged by talk of voluntarily believing that $p$, the ambiguity of which inclines me not to characterize voluntarism in quite this way myself - at least, not in this context. The reason for this is that the version of voluntarism for which I argue is not properly described as doxastic voluntarism, which is precisely what 'voluntarily believing that $p$ ' suggests, as though one could simply flip a switch (on a whim, even, hence the impression of whimsicality) and believe anything one might like, if only one sincerely tried to flip it. Conversely, I argue for a voluntarism about epistemic stances. This is to say that there is a form of choice involved in our adoption of stances, which are some distance upstream from the formation

\footnotetext{
19 Bryant, Section 5.

20 Psillos, Section 5.
} 
of beliefs, though nevertheless part of what determines — in addition to our evidence - the doxastic states we end up with. Thus, it is only in this more indirect way that voluntarism applies to belief.

Admittedly, this merely pushes the worry upstream, into the region of stances themselves, and here a second assumption plays a pivotal role in motivating concern. This assumption, which Bryant and Psillos do appear to make, is that adopting a stance involves an implausible sort of choice, possibly on the model of choosing to believe that it is raining, or that one is 6 foot 3 inches tall. I submit, however, that this gives the wrong impression of what 'choice' means in this context. What 'choice' means here is simply that one adopts one from among apparently reasonable or acceptable options. Imagine that it is raining in Vancouver and you stop to buy an umbrella. The shop has a few; they are identical with regard to form, function, and quality, but there are several different colours. Perhaps the yellow one strikes you as the right one for you the yellow resonates with you, it feels right, and that is the one you take. We could even imagine that you are so enamoured of yellow that you could not have done otherwise. You may not even be consciously aware that you are acting in this way. All of this said, there is a clear sense in which you had a choice. To say that there is something voluntary about adopting a stance appeals to this sense regarding options. If more than one of them is defensible as reasonable (the question to which I turn in the next section), one cannot be faulted for going one way or another. Given one's attitudes, values, etc., one gravitates toward and takes one. That is what 'choice' means here. ${ }^{21}$

With this clarification in hand, it may be possible to clear up some smaller worries about the idea that different people choose differently before turning to larger ones. Earlier, I claimed that stances function to help epistemic agents draw lines between domains of theorizing that they regard as amenable to belief, and ones that they regard as better suited to suspension of belief. In the book, I further assert that this prevents different choices of stance from amounting to an unhappy form of epistemic relativism, according to which, armed with different stances, one agent asserts $p$ and another $\sim p$ — in other words, differential choices of stance do not license contradictions. Bryant worries that this seems rather convenient, suspiciously so, perhaps even a "brute stipulation."22 After all, do we not frequently encounter debates about ontology in which

21 This clarification resolves, I hope, Bryant's concern (in her Section 5) that stance voluntarism is an empirical hypothesis lacking empirical evidence. Whatever the relevant empirical psychology may be, it is not required to establish the reality of choice as described here. This leaves open, I think, the question of whether (this corner of) epistemology is amenable to being naturalized in the sense of being replaceable (ultimately or in principle) by psychology. For preliminary remarks on this, see Chakravartty, 2017, 221-222.

Bryant, Section 4. 
interlocutors believe and disbelieve one and the same ontological proposition, presumably in part as a consequence of holding different stances? As an example of this, Psillos considers my discussion of (what I describe as) dilemmas that inquirers inevitably face when forced to reckon with the bedrock assumptions on which their ontological commitments rest. ${ }^{23}$ One instance, which he has himself discussed in detail over a period of decades, is that of different versions of structural realism in physics. If such disputes are commonplace - and, of course, they are - what is left of the assertion that different stances do not license contradictory beliefs?

In the case of forms of structuralism, it is clear that advocates of different physical ontologies endorse contrary descriptions of what is fundamental: on the one hand, concrete relations that lack relata, and on the other hand, concrete relations that have objects as their relata, but objects whose properties are all and only extrinsic. $^{24}$ These conflicting descriptions, however, are not reflective of a clash between stances. Recall, a stance determines whether a domain of inquiry is a good bet for warranted belief; if not, the upshot is agnosticism. In the example of structural realism, the disputants each argue for the correctness of their ontological picture of the domain. Hence, the differences between them cannot be explained in terms of holding different stances. To the extent that each takes the evidence in this domain to be compelling, they share a stance according to which it is - while disagreeing about which ontological picture is correct. My consideration of these sorts of examples is not intended to illuminate the nature of stances per se, but rather to illustrate how difficult it is to settle ontological disputes in contexts of highly attenuated empirical vulnerability. In these contexts, I suggest, correspondingly attenuated degrees of belief may well seem appropriate, perhaps even tending toward suspension of belief and/or a more pragmatic as opposed to realist attitude toward the propositions at issue.

What about the case of conflicts between Humeanism and (one brand of) realism about laws of nature, which differ on whether there are relations of nomic necessitation between properties - the former denying the idea and the latter asserting it? Here, I think, some care is required regarding the ambiguity of terms such as 'Humeanism.' What is it? Sometimes we have in mind the adoption of a version of the empiricist stance that we take to resemble Hume's, perhaps including an aversion to projecting certain ideas (e.g., about necessary connections) onto the world. This all by itself is compatible with an agnosticism

23 Psillos, Section 4.

24 As Psillos (ibid.) notes, these are not the only options. He and I have both argued against various forms of structuralism and in favour of other views (e.g., Psillos, 2006; Chakravartty, 2007), but this does not support his reaction to this example (why not simply "reject the common presupposition, viz. structuralism"?), because examples such as these may be iterated to include further options (such as his or mine) at will. 
about what, precisely, the world is like in these respects. Conversely, we sometimes have in mind a very different conception of Humeanism, as incorporating specific answers to ontological questions in the form of comparatively austere descriptions as opposed to more elaborate ones. On this latter conception, contrary to the realist about laws, the Humean asserts that there are no such things as relations of nomic necessitation. In this case, the Humean and the realist take contradictory positions regarding an ontological proposition, but note: in so doing, both take the relevant evidence and arguments to be telling. Humeanism in this sense is not an agnosticism about certain metaphysical issues, indicative of a stance; it is an answer to certain metaphysical questions. Arguing for a Humean metaphysic is an exercise in the metaphysics of a domain.

This last observation may evoke van Fraassen's own motivations for describing empiricism as a stance, not a 'doctrine': the latter, he thinks, is self-defeating in part because it requires a form of engagement with metaphysics that he takes empiricism (properly conceived) to disavow. ${ }^{25}$ I myself am happy to countenance both conceptions so long as we are clear about which we have in mind and do not conflate them. And it may be that a preference for desert landscapes, with concomitant values such as a distaste for the proffered explanatory power of lusher ontological posits, are elements of both conceptions of Humeanism. ${ }^{26}$ Elsewhere, I would be tempted to argue that, when it comes to Humean metaphysics - the latter conception - claims of austerity are often overstated. That is, the extent to which ontologies associated with this sort of Humeanism are lightweight qua metaphysics, as compared to rival views, is debatable. Humean regularities, for instance — invariable, inescapable patterns imbuing the warp and weft of the world, past, present, and future - are arguably not especially metaphysically innocent. But this is not the place to prosecute a debate about the metaphysics of laws, only to note that the existence of such disputes does nothing to undermine the notion of an epistemic stance.

\section{A Permissive Conception of Rationality for Epistemic Stances}

Having defended an account of metaphysical inferences, of how assessments of their magnitudes inform judgements of epistemic risk in accordance with underlying stances, and of the nature of voluntarism in this context, let me turn now, finally, to what I earlier described as the normative piece of the puzzle. As soon as voluntarism enters the picture, an immediate concern arises that this must somehow preclude any form of justification for belief - that somehow, from

25 van Fraassen, 2002.

26 In retrospect I worry that I was not sufficiently clear about this in Chapter 4 (Chakravartty, 2017), where I consider realism and empiricism regarding dispositions, to prevent this conflation on the part of my readers. That said, I hope the conclusion of this chapter (130-131) does the trick. 
a normative point of view, allowing that different agents may adopt different stances is equivalent to throwing open the floodgates to epistemic anarchy: ${ }^{27}$ anything goes, believe what you like! This is not the case, but in order to appreciate this, one must take a meta-level perspective on belief formation: one must consider not only why and how certain propositions appear warranted (or not) to oneself, or to others very much like oneself, but also why and how they seem warranted (or not) to others who differ from us in this respect. Clearly, pursuing this sort of out-of-body, other-minds-type experience is not a trivial exercise, but it is essential, I submit, if we are to understand the nature of justification simpliciter, not merely the nature of our own justifications. I suspect that many impulsive reactions to voluntarism stem from being trapped within one's own assessments. Thus trapped, it appears that there is only one, truly rational, epistemic stance. Coincidentally, it happens to be one's own.

In this last section of my reply, I would like to suggest that many worries about stance voluntarism and the permissive conception of rationality that goes with it do not, in fact, stem from arguments against these views, nor even arguments for alternative views. They are expressions of a perhaps inevitable unease that accompanies the possibility that one's own beliefs are not uniquely rational. By describing things this way, I do not mean to discount the concern. It is serious and genuine - especially if one is worried that a descent into epistemic anarchy hangs in the balance. With a nod to the last chapter of the book, in which I attempt to map a road toward coping with feelings of disquiet about permissivism that arise even in the absence of anarchy, let me focus here on defending the assertion that this understanding of rationality, and hence justification, does not permit just any belief profile and associated stance. Rather, it places constraints involving logical and pragmatic coherence, where the latter is exemplified (in part) when a stance is not self-defeating in the sense of facilitating beliefs that are in some way at odds with the attitudes and values comprising it. Admittedly, these strictures are minimal (thus generative of permissivism), but the range of stances they permit nonetheless excludes candidates that fall foul of them. ${ }^{28}$ The obvious question then becomes: is there reason to think that justification can be more restrictive?

Consider Slater's query regarding the seeming intractability of debates between scientific realists and antirealists. Might one simply dissolve or cut

27 Bryant uses the phrase "epistemic anarchy" in both her title and in her Section 4.

28 In his Section 5, Psillos disputes this in passing, on the basis of my contention that false or inconsistent beliefs do not necessarily indicate the incoherence of a stance. This contention follows from the fact that different sets of beliefs may be compatible with one and the same stance, and inconsistent sets may be revised within the scope of this compatibility. This allows, of course, for cases in which stances seem incapable of generating, or seem very unlikely to generate consistent beliefs, which may well indicate their irrationality. 
through the morass by appropriately filling in the details of a reaction such as this?:

Something in the ballpark of scientific realism is pretty clearly the most reasonable take. The 'debate' persists ... because some of the disputants are being unreasonable. It is unreasonable not to believe in atoms or electrons or carbon nanotubes or DNA, despite the fact that these items are unobservable ... ${ }^{29}$

It should now be clear, I hope, why I see nothing promising here. If such a reaction is to amount to something more than an indication of a stance to which one is committed, underlying one's scientific realism, it should point to a non-question-begging critique of a rival stance or stances held by antirealists, but what is that? Perhaps one could say that positing underlying unobservable entities yields a satisfyingly fulsome image of the world, one that would quench our thirst for various forms of (causal, nomological, etc.) explanation, and that thankfully, as it happens, our evidence strongly supports belief in various unobservable parts of this image. Herein lies the difficulty, however. We have here no reason to think that what is most reasonable, what compels us toward ontological commitment - in assessing epistemic risk based on empirical vulnerability and explanatory power - is uniquely forced. Lacking here is an argument for unique forcing — one that does not simply beg the question against those holding a different stance. Such an argument is hard to fathom. While believing in the reality of certain entities may be required in order to believe a more (rather than less) fulsome description of the world, assessments of the warrant for such descriptions, with all of the ontological commitment this entails, are not. ${ }^{30}$

None of this precludes debate between agents holding different stances and, indeed, subsequent revisions to both stances and beliefs, in all of the ways that Slater suggests when he adverts to uncovering possible failures of consistency and coherence. ${ }^{31}$ A voluntarist about stances should welcome debate as a mechanism for testing their rationality, and the example of ongoing disputes between scientific realists and antirealists furnishes an excellent illustration. Eons of

Slater, Section 2.

This point is related to why I do not affirm Bryant's suggestion (in her Section 4) that the account of rationality yielding permissivism itself belongs to a stance, and that different stances could incorporate different accounts (cf. Slater, Section 3, on "metastances" regarding rationality). I cannot do this suggestion justice here, but let me note two things: a theory of rationality is not, of course, an ontological claim; furthermore, permissivism is motivated and supported by our actual, differential, epistemic practices, and a corresponding absence of ultimately non-question-begging arguments for impermissivism.

31 Slater, Section 3. I do not think that this requires a hierarchy of stances, though - a feature of Slater's view to which I will turn momentarily. 
spirited debate has resulted, I believe, in the evolution of versions of scientific realism, antirealism, and underlying stances that are increasingly coherent and, thereby, defensible. That said, and as this particular example demonstrates, the possibility and importance of debate is no guarantee of resolution. A striking lack of resolution in this case is unsurprising given that, as I have suggested, versions of the empiricist and metaphysical stances underlying certain forms of scientific realism and antirealism are, in fact, rational (in the sense sketched above). Those who are very familiar with these debates may not be surprised by the claim that, given the resilience of certain underlying stances throughout the evolution of disputes between scientific realists and antirealists, and the ways in which many of the tracks of this debate have culminated in stalemates, we have at least prima facie evidence that the underlying stances are rational. Even spirited debate has been incapable, it seems, of revealing any clear-cut, internal incoherence, and that is why the debate is unresolved.

Despite an openness to debate, I expect that some may yet view these claims as defeatist. Much like Bryant and Slater, Paul Teller has wondered whether there might be deeper, shared attitudes and values to which one might appeal in order to argue for the superiority of one minimally rational stance over another. $^{32}$ I am sceptical about this. Anything so deep as to be shared, such as a generic desire to know truths, or a blanket distaste for believing falsehoods, seems likely to be characterized so abstractly as to be exemplified by any minimally rational stance, and not in a way that suggests the possibility of non-question-begging arguments for one over another. At this level of abstraction and broad agreement, the relevant attitudes and values will be (presumably) highly underspecified and multiply realizable, allowing for different realizations in conflicting but nonetheless rational stances. Thus, once again, progress in debates about rational stances is likely to take the form of refinement improved articulations, understandings, and defences - not ultimate victories and defeats.

Undaunted, Slater suggests that attention to cases may yet reveal significantly less abstract commitments (norms, values) shared by those adopting rival stances. These commitments would comprise a "higher-order epistemic stance," facilitating determinations of which among rival stances are preferable. ${ }^{33}$ The cases he adduces are ones of classificatory pluralism within a scientific domain, the viability of which we have both defended. ${ }^{34}$ The location of disputes about classification within domains, however, already suggests that epistemic stances are not what is at issue in these cases. A stance determines whether its holder views a domain of inquiry as one in which beliefs regarding its subject matter

32 Bryant, Section 3; Slater, Section 3, regarding "(presumptively) shared norms"; Teller, 2004.

33 Slater, Section 3.

34 Chakravartty, 2011; Slater, 2013. 
are warranted. When astronomers debate whether criteria for classifying bodies as planets should include only intrinsic features, or also extrinsic features (e.g., relations to other orbital bodies), or when biologists debate whether taxa should be only monophyletic, or also polyphyletic, they all take beliefs about the relevant categories, however properly demarcated, to be warrantable. Slater and I (and others) agree, I believe, that ultimately, decisions about how best to demarcate categories of things are properly made by considering what question(s) a given inquiry poses; different groupings may be optimal for answering different questions. $^{35}$ This, I take it, is quite unlike the case of rival stances, where the issue is not that of determining what tool (group of entities) best suits answering a question, but that of determining whether any answer can be warranted at all.

Let me close with a worry that is pressing not merely in the seminar room but also outside of it, in the public sphere. The concern is that if epistemic rationality is permissive in the sense I claim it is, we have no resources with which to argue against epistemic malpractice of the sort we find in cases of pseudoscience, and in cases of what one might call 'pretend science,' wherein I would include various forms of malfeasance such as manipulations of scientific work (e.g., through funding effects) and the complicit promotion of intentionally misleading descriptions of scientific results (e.g., in order to promote social, economic, and political agendas). According to the permissive conception, the test of rationality is ultimately coherence, both logical and pragmatic. And surely, one might argue, it is possible that at least some creationists and climate change deniers are coherent. Just as surely, insofar as their beliefs about the evolution of organisms and the global climate are concerned, they are irrational. Presto, reductio; there must be something wrong with permissivism. Perhaps predictably, I certainly agree that the widespread turmoil caused by pseudoscience and pretend science, epistemically and otherwise, is a mighty challenge to be faced. However, I do not think that permissive rationality, as I have described it, ties our hands in facing it; and neither do I think that impermissivism would better empower us. To see why, let me first note some qualifications.

Throughout the book, I am careful to stress that my interest is in epistemic stances, though surely there are other kinds. Psillos is happy to grant, I believe, that an epistemic stance is, by definition, one that is relevant to the production of knowledge, and that evidence is, by definition, that which is relevant to the truth or falsity of a proposition. He balks, however, at the conclusion I draw from this: to the extent that one is engaged in an epistemic inquiry informed by an epistemic stance, one cannot disregard or otherwise mismanage evidence, on pain of incoherence and thus irrationality. ${ }^{36}$ So, let me say more: if creationists discount

35 I call this "pluralism about packaging" (Chakravartty, 2017, Chapter 6) - a view which, furthermore, is premised on agreement regarding the basic ontology of members of possible categories in a domain.

36

Psillos, Section 5. 
certain aspects of the empirical evidence because to do so serves a religious purpose, or if governors of Florida maintain that there is no scientific consensus regarding anthropogenic climate change because to do so serves a political purpose, they are guilty of disregarding or mismanaging the evidence. The former may be operating with a religious stance and the latter a political stance, but neither seems to be operating with an epistemic stance, as conceived within the context of domains of naturalized metaphysics that I have aspired to describe.

This last qualification delimits the scope of my epistemological ambitions. Recall the sense in which, in this context, empiricism won its debate. No one who shares a genuine interest in scientific ontology, whether an instrumentalist, a logical empiricist, a constructive empiricist, a minimal realist, or a much-less-minimal realist, fails to give empirical evidence its due. ${ }^{37} \mathrm{Be}$ that as it may, is it nevertheless possible that creationists and climate change deniers operate with broader, not-merely-epistemic stances - this is how I would characterize those whom Slater describes as having (arguably) "odd epistemic risk profiles",38 — that are internally coherent? It is difficult to rule out such things by fiat, but now, having shifted the focus of our analysis from the realm of strictly epistemic norms, as delimited above, to a much larger territory where other norms roam freely and deference to empirical inquiry and the evidential weight of empirical vulnerability may have little or no purchase, the terms of the debate must shift accordingly.

I claim no special efficacy for epistemic stances and permissive rationality in this larger, more complex arena, but before conceding too much, it is worth noting two things. First, even if epistemic rationality were not at all permissive in the way I take it to be - take it to be as impermissive as you like - this would confer no advantage in disputes with those for whom epistemic norms are discounted, or viewed as subservient to other kinds of norms, even in belief formation. Neither the permissivist nor the impermissivist has a magic wand of persuasion. Second, and on the flip side, perhaps there is a saving grace here either way, which the permissivist would put this way: creationism, climate change denial, etc., are not stances. They are putatively factual claims. As such, their advocates must take their chances in debates with people who hold opposing views, some of whom will, I expect, have rational epistemic stances. That is exactly as it should be and, in any case, it is the best we can do in challenging times.

37 Others have more extensive ambitions, for example, Schoenfield, 2014. My qualifications here partially address Bryant's speculations, in her Section 4, about how far my account is intended to extend. They likewise exclude possible agents described by Slater, in his Section 3, who assess epistemic risk in ways that do not (consistently) take empirical vulnerability seriously.

Slater, Section 3. 


\section{Acknowledgements}

I am grateful to Kerry McKenzie for organizing the session at which this discussion began (at the Pacific Division meeting of the American Philosophical Association in Vancouver, 2019), to Alan Richardson and our audience for their insightful interventions, and (once again) to Amanda Bryant, Stathis Psillos, and Matt Slater for their acuity and constructive spirit, and their kindness in reworking their papers for this symposium.

\section{References}

Bryant, A.

2021 "A Thousand Flowers on the Road to Epistemic Anarchy: Comments on Chakravartty's Scientific Ontology," Dialogue 60(1): 1-13.

Chakravartty, A.

2007 A Metaphysics for Scientific Realism: Knowing the Unobservable. Cambridge: Cambridge University Press.

Chakravartty, A.

2011 "Scientific Realism and Ontological Relativity," The Monist 94(2): $157-180$.

Chakravartty, A.

2017 Scientific Ontology: Integrating Naturalized Metaphysics and Voluntarist Epistemology. New York: Oxford University Press.

Fine, A.

1996/1986 The Shaky Game: Einstein, Realism and the Quantum Theory, $2^{\text {nd }}$ edition. Chicago: University of Chicago Press.

Lipton, P.

2004/1991 Inference to the Best Explanation. London: Routledge.

Psillos, S.

1999 Scientific Realism: How Science Tracks Truth. London: Routledge.

Psillos, S.

2006 "The Structure, the Whole Structure, and Nothing but the Structure?," Philosophy of Science 73(5): 560-570.

Psillos, S.

2021 “Scientific Ontology: Fact or Stance?," Dialogue 60(1): 15-31.

Schoenfield, M.

2014 "Permission to Believe: Why Permissivism is True and What It Tells Us About Irrelevant Influences on Belief," Noûs 48(2): 193-218.

Slater, M.H.

2013 Are Species Real?: An Essay on the Metaphysics of Species. London: Palgrave Macmillan.

Slater, M.H.

2021 "Extending the Ladder of Stances: Comments on Chakravartty's Scientific Ontology,” Dialogue 60(1): 33-42. 
Teller, $\mathrm{P}$.

2004 "Discussion - What Is a Stance?," Philosophical Studies 121(2): 159-170.

van Fraassen, B.C.

2002 The Empirical Stance. New Haven: Yale University Press.

Worrall, J.

2000 "Tracking Track Records II," Aristotelian Society Supplementary Volume 74(1): 207-235.

Wylie, A.

1986 "Arguments for Scientific Realism: The Ascending Spiral," American Philosophical Quarterly 23(3): 287-297. 